\title{
Highly Sensitive Voltammetric Determination of Acrylamide Based on Ibuprofen Capped Mercury Nanoparticles
}

\author{
Sirajuddin ${ }^{1}$, Zulfiqar Ali Tagar ${ }^{2}$, Muhammad Anwar Ul Haq ${ }^{1}{ }^{1}$, Muhammad Raza Shah ${ }^{1}$, Mujeeb-ur-Rehman ${ }^{1}$, \\ Syed Tufail Hussain Sherazi ${ }^{2}$, Jiri Barek ${ }^{3, *}$ and Muhammad Siddique Kalhoro ${ }^{4}$ \\ 1 International Center for Chemical and Biological Sciences, HEJ Research Institute of Chemistry, University of \\ Karachi, Karachi 75270, Pakistan; drsiraj03@yahoo.com (S.); anwarulhaq196@gmail.com (M.A.U.H.); \\ raza.shah@iccs.edu (M.R.S.); mbtk.chem@gmail.com (M.-u.-R.) \\ 2 National Center of Excellence in Analytical Chemistry, University of Sindh, Jamshoro 76080, Pakistan; \\ tagarzulfiqar@gmail.com (Z.A.T.); tufail.sherazi@gmail.com (S.T.H.S.) \\ 3 UNESCO Laboratory of Environmental Electrochemistry, Department of Analytical Chemistry, Faculty of \\ Science, Charles University, Albertov 6, CZ-15843 Prague, Czech Republic \\ 4 Institute of Physics, University of Sindh, Jamshoro 76080, Pakistan; mskalhoro@hotmail.com \\ * Correspondence: barek@natur.cuni.cz
}

check for updates

Citation: Sirajuddin; Tagar, Z.A.; Ul Haq, M.A.; Shah, M.R.;

Mujeeb-ur-Rehman; Sherazi, S.T.H.;

Barek, J.; Kalhoro, M.S. Highly

Sensitive Voltammetric

Determination of Acrylamide Based on Ibuprofen Capped Mercury

Nanoparticles. Sensors 2021, 21, 7302.

https://doi.org/10.3390/s21217302

Academic Editor: Silvana Andreescu

Received: 23 August 2021

Accepted: 28 October 2021

Published: 2 November 2021

Publisher's Note: MDPI stays neutral with regard to jurisdictional claims in published maps and institutional affiliations.

Copyright: (c) 2021 by the authors. Licensee MDPI, Basel, Switzerland. This article is an open access article distributed under the terms and conditions of the Creative Commons Attribution (CC BY) license (https:/ / creativecommons.org/licenses/by/ $4.0 /)$.

\begin{abstract}
Highly stable, small-sized and evenly distributed solid mercury nanoparticles capped with ibuprofen (Ibu-HgNPs) were prepared via reduction with hydrazine and capped with ibuprofen as a stabilizing agent. Characterization of Ibu-HgNPs was carried out by UV-Vis spectrophotometry and transmission electron microscopy (TEM). The prepared Ibu-HgNPs were immobilized onto a glassy carbon electrode (GCE) and used for the first time as the sensing element for voltammetric determination of low concentrations of acrylamide (AA) in aqueous solutions. Various parameters such as the type of supporting electrolyte, voltammetric mode, frequency, deposition time, stirring rate and initial potential were optimized to obtain the highest peak current of AA. The sensor delivered the best results in combination with the square wave voltammetry (SWV) mode, with good repeatability (relative standard deviation (RSD) of 25 repetitions was $1.4 \%$ for $1000 \mathrm{ppb}$ AA). The study further revealed that Ibu-HgNPs are strongly adhered to GCE and hence do not contaminate the environment even after several runs. The newly developed AA sensor provides linear calibration dependence in the range of 100-1300 ppb with an $\mathrm{R}^{2}$ value of 0.996 and limit of detection (LOD) of $8.5 \mathrm{ppb}$. Negligible interference was confirmed from several organic compounds, cations and anions. The developed sensor was successfully applied for AA determination in various types of environmental real water samples to prove its practical usefulness and applicability.
\end{abstract}

Keywords: mercury nanoparticles; ibuprofen; square wave voltammetry; acrylamide sensor; real water samples

\section{Introduction}

Acrylamide (AA) is an industrially important hydrophilic organic compound applied globally to produce polyacrylamide (PAA), which is used in various fields (e.g., as flocculent and coagulant agent, as grouting agent for water pipes, tunnels, cosmetics, plastics, paper and textile industries and in the form of a solid support for proteins' separation via electrophoresis). Owing to hydrogen bonding, AA is easily soluble in water and hence easily movable in the environment. Release of the AA monomer from PAA in related industries, soil grouting and other situations is a major cause of water pollution. According to the International Agency for Research on Cancer (IARC), AA and its epoxide metabolites are toxic to reproductive system, neurotoxic and carcinogenic [1-4]. Several methods have been reported so far for AA determination including liquid chromatography with pulsed electrochemical detection (LC ED) [5], ion exclusion liquid chromatography coupled with diode array detection (LC-DAD) [6], gas chromatography with electron capture 
detector (GC-ECD) [7], liquid chromatography coupled with tandem mass-spectrometry (LC-MS/MS) [8], liquid chromatography-mass spectrometry (LC-MS) [9], combination of ion-exclusion chromatographic separation and MS detection [10], reversed-phase highperformance liquid chromatography (RP-HPLC) [11], normal phase HPLC [12], HPLC MS-MS [13], colorimetry [14] and fluorescence spectroscopy [15]. However, voltammetric methods are considered the most economical, simple and sensitive, based on portable and inexpensive instrumentation and a simple redox reaction, and they provide a high sensitivity and reasonable selectivity. Catalytic square wave voltammetry at a hanging mercury drop electrode [16] is a good example with a limit of detection (LOD) around $4 \mathrm{ppb}$. Niaz et al. developed a differential pulse polarographic (DPP) method for the determination of AA directly in a neutral $0.05 \mathrm{~mol} \mathrm{~L}^{-1} \mathrm{LiCl}$ aqueous solution using a dropping mercury electrode (DME). At optimum conditions, the calibration graph was linear in the concentration range from $0.2 \mathrm{ppm}$ to $20 \mathrm{ppm}$ [17]. Due to fear of mercury toxicity, attempts have been made to use various modified electrodes to make the electrochemical method more economical, sensitive and environmentally friendly. For instance, single-walled carbon nanotubes (SWCNTs) and hemoglobin ( $\mathrm{Hb}$ )-modified glassy carbon electrodes (GCE) have been used for voltammetric detection of AA with very low LOD $1.0 \mathrm{ppb}$ in aqueous extracts from potato crisps [18]. An imprinted sol-gel polymer on an AuNPs-MWCNTs-CS modified electrode [19] and hemoglobin-oligonucleotides-modified electrode [20] was also successfully used for the determination of AA.

In the present paper, we use another novel strategy for electrode modification. We synthesize mercury nanoparticles (HgNPs) via reduction of $\mathrm{Hg}^{2+}$ ions by hydrazine, capping them with ibuprofen (see Figure 1) as the stabilizing agent. These HgNPs were deposited on the surface of GCE and applied as a highly sensitive and selective principally novel type of voltammetric modifier for AA detection in various types of water samples.<smiles>C=CC(N)=O</smiles>

Figure 1. Structural formulas of acrylamide (left) and ibuprofen (right).

\section{Materials and Methods}

\subsection{Reagents and Materials}

Mercuric chloride $\left(\mathrm{HgCl}_{2}\right)$, sodium hydroxide $(\mathrm{NaOH})$, hydrazine $\left(\mathrm{N}_{2} \mathrm{H}_{2}\right)$, $\mathrm{Nafion}{ }^{\mathrm{TM}}$, ibuprofen, potassium nitrate $\left(\mathrm{KNO}_{3}\right)$, sodium chloride $(\mathrm{NaCl})$, calcium nitrate $\left(\mathrm{Ca}\left(\mathrm{NO}_{3}\right)_{2}\right)$, ammonium nitrate $\left(\mathrm{NH}_{4} \mathrm{NO}_{3}\right)$, acrylamide (electrophoresis grade) and lithium chloride $(\mathrm{LiCl})$ (all analytical grade) were obtained from E. Merck; tetramethylammonium bromide (TMAB), tetramethylammonium iodide (TMAI) and tetrabutylammonium iodide (TBAI) from Fluka; nitric acid $\left(\mathrm{HNO}_{3}\right)$, acetone, acrolein, acrylic acid, maleic acid, glucose, citric acid and starch from BDH, and potassium chloride from Sigma-Aldrich. Stock solution of $0.5 \%$ ibuprofen was prepared in methanol. $0.5 \%$ Nafion $^{\mathrm{TM}}$ solution was prepared in iso-propanol via intensive sonication. Stock solutions of $0.02 \mathrm{~mol} \mathrm{~L}^{-1} \mathrm{HgCl}_{2}, 0.4 \mathrm{~mol} \mathrm{~L}^{-1}$ $\mathrm{NaOH}, 0.05 \mathrm{~mol} \mathrm{~L}^{-1} \mathrm{LiCl}, \mathrm{TMAB}, \mathrm{TBAB}, \mathrm{TMAI}$ and TBAI and all other salts solutions were prepared in milli $Q^{\circledR}$ deionized water $(100 \mu \mathrm{S} / \mathrm{cm})$.

\subsection{Apparatus}

Ibu-HgNPs were characterized via UV-Vis spectrophotometry (Lambda 2) of Perkin Elmer in the range of $200-800 \mathrm{~nm}$. Scanning transmission electron microscopy (STEM) imaging was carried out using a model TECNAI F300 electron microscope (FEI Company) 
working at an accelerating power of $200 \mathrm{kV}$, while voltammetric study was performed by a VA 797 Trace Analyzer from Metrohm, Switzerland using Ibu-HgNPs-GCE as a working electrode, $\mathrm{Ag} \mid \mathrm{AgCl}\left(3.5 \mathrm{~mol} \mathrm{~L}^{-1} \mathrm{KCl}\right)$ as a reference electrode and $\mathrm{Pt}$ rod as a counter electrode (see Section 2.5).

\subsection{Synthesis of $\mathrm{Ibu}-\mathrm{HgNPs}$}

Ibu-HgNPs were synthesized according to [21]. Briefly, $1.2 \mathrm{~mL}$ of $0.02 \mathrm{~mol} \mathrm{~L}^{-1} \mathrm{HgCl}_{2}$ solution was diluted to $10 \mathrm{~mL}$ with milli $\mathrm{Q}^{\circledR}$ water and its $\mathrm{pH}$ was adjusted to 1.5 by adding $1 \mathrm{~mol} \mathrm{~L}^{-1} \mathrm{HCl}$. To this solution, $90 \mu \mathrm{L}$ of $0.4 \mathrm{~mol} \mathrm{~L}^{-1} \mathrm{NaOH}$ was added followed by $150 \mu \mathrm{L}$ of $0.1 \mathrm{~mol} \mathrm{~L}^{-1}$ hydrazine and $400 \mu \mathrm{L}$ of $0.5 \%$ ibuprofen solution in the mentioned order with the final adjustment to $20 \mathrm{~mL}$ by milli $\mathrm{Q}^{\circledR}$ water. The solution was mixed by stirring with a glass rod for $1.5 \mathrm{~min}$ until a slightly whitish milky solution was formed with a $\mathrm{pH}$ of $4.0 \pm 0.1$.

\subsection{STEM Characterization of $\mathrm{HgNPS}$}

Samples for STEM characterization were prepared by placing a drop of Ibu-HgNPs solution prepared by the above-described procedure on a carbon-coated copper grid and drying under a vacuum at room temperature.

\subsection{Cleaning and Modification of Glassy Carbon Electrode}

A glassy carbon electrode (GCE, $3 \mathrm{~mm}$ diameter) was cleaned first by polishing with aqueous paste of $0.05 \mu \mathrm{m}$ alumina followed by sonication in milli $\mathrm{Q}^{\circledR}$ water for $5 \mathrm{~min}$ and drying under pure nitrogen. A $5 \mu \mathrm{L}$ drop of $0.5 \%$ Nafion $^{\mathrm{TM}}$ solution was deposited on the surface of GCE and dried with a hair dryer, and another similar drop was applied over GCE and dried again in the same way. Afterwards, a $5 \mu \mathrm{L}$ drop of Ibu-HgNPs was placed over the layer of Nafion ${ }^{\mathrm{TM}}$ treated GCE and dried in the same way as in the case of Nafion ${ }^{\mathrm{TM}}$ deposition. Afterwards, the prepared modified GCE further denoted as Ibu-HgNPs-GCE was used as a working electrode for AA detection in all further studies.

\subsection{Voltammetric Studies}

Cyclic voltammetry (CV), square wave voltammetry (SWV) and differential pulse voltammetry (DPV) were used in following voltammetric studies. A three-electrode arrangement was used with Ibu-HgNPs-GCE as the working electrode, $\mathrm{Ag} \mid \mathrm{AgCl}\left(3.5 \mathrm{~mol} \mathrm{~L}^{-1}\right.$ $\mathrm{KCl})$ as the reference electrode and a Pt rod as the counter electrode. In this study, $20 \mathrm{~mL}$ $0.05 \mathrm{~mol} \mathrm{~L}^{-1} \mathrm{LiCl}$ mixed with $0.05 \mathrm{~mol} \mathrm{~L}^{-1} \mathrm{TMAB}$ in an 8:2 $v / v$ ratio $(\mathrm{pH} 6.9 \pm 0.1)$ was used as a supporting electrolyte unless stated otherwise. Nitrogen purging for $240 \mathrm{~s}$ was used to remove dissolved oxygen. For the $\mathrm{CV}$ scan rate $100 \mathrm{mVs}^{-1}$ was used unless stated otherwise. SWV in the potential range from -0.1 to $-2.0 \mathrm{~V}$ with a frequency of $50 \mathrm{~Hz}$ was used unless stated otherwise. For DPV, the following parameters were used unless stated otherwise: scan rate $20 \mathrm{mVs}^{-1}$, pulse amplitude $50 \mathrm{mV}$, pulse width $100 \mathrm{~ms}$.

\subsection{Application of Ibu-HgNPs-GCE to Tap Water Samples and River Indus Water Samples}

The tap water sample was collected from the Electrochemistry and Nanotechnology Laboratory building at the University of Sindh, while river water samples were collected from three different sites of River Indus: Hyderabad Division, Sindh, Pakistan. For the research, $10 \mathrm{~mL}$ of $0.05 \mathrm{~mol} \mathrm{~L}^{-1} \mathrm{LiCl}$ and $0.05 \mathrm{~mol} \mathrm{~L}^{-1} \mathrm{TMAB}$ mixture $(8: 2 v / v)$ in deionized water was made to $20 \mathrm{~mL}$ with tap water containing $200 \mathrm{ppb}, 500 \mathrm{ppb}$ and $700 \mathrm{ppb}$ of AA. Each sample was analyzed in triplicate using parameters described in Section 2.6. Samples collected from the River Indus were first filtered using Whatman filter paper No. 1 and then handled in the same way as the tap water samples. 


\section{Results and Discussion}

3.1. Characterization of Modified Electrode (Ibu-HgNPs-GCE)

3.1.1. UV-Vis Spectrophotometry

The UV-Vis spectrum of HgNPs, formed using hydrazine as a reducing agent and ibuprofen as a capping agent, is depicted in Figure 2.

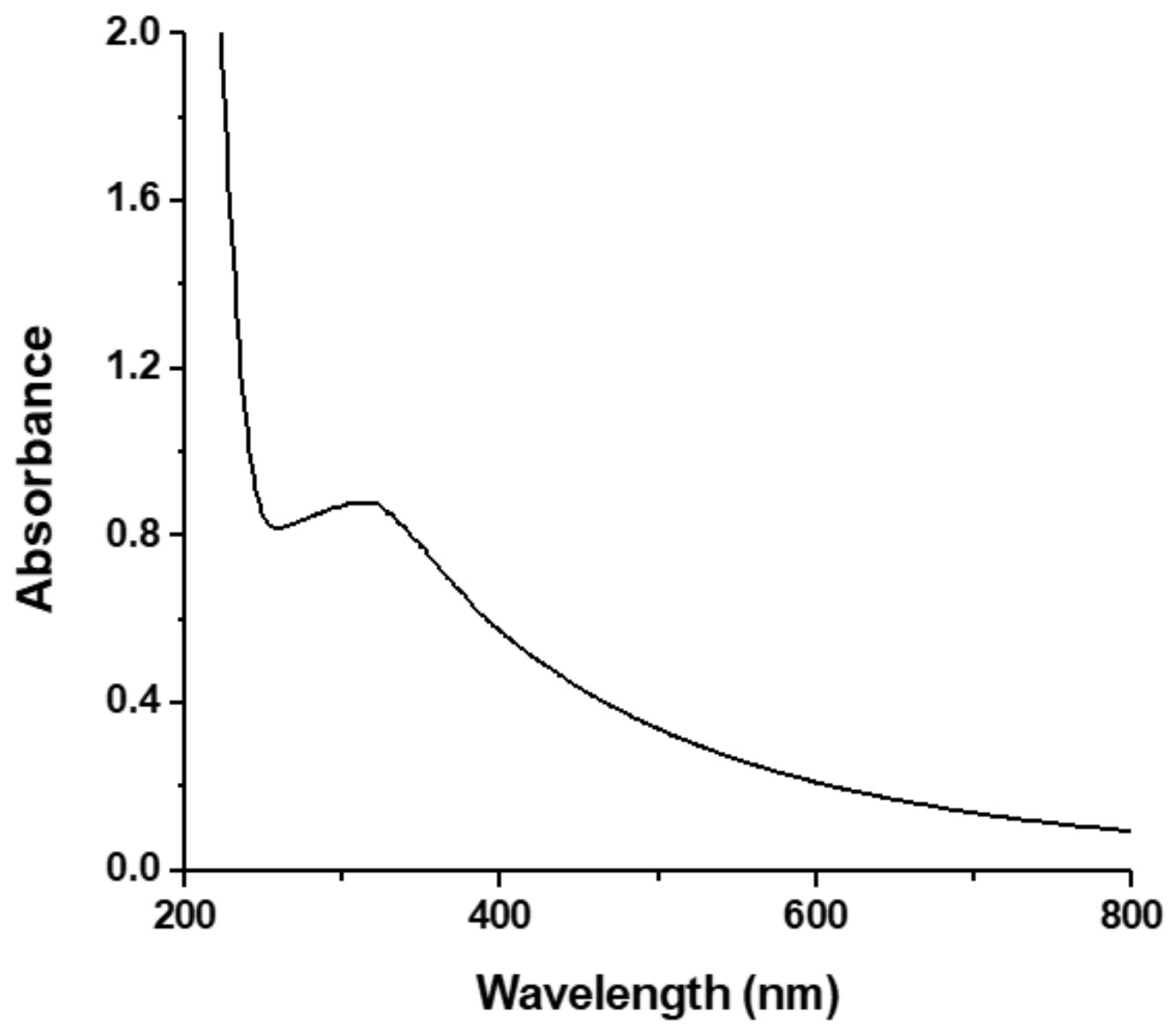

Figure 2. UV-Vis spectrum of Ibu-HgNPs prepared under optimized conditions stated in Section 2.3 using milli $\mathrm{Q}^{\circledR}$ water as blank. Optical path length $10 \mathrm{~mm}$.

This UV-Vis spectrum corresponds to a previously published one [19] and confirms the formation of ibuprofen capped HgNPs under these conditions.

\subsubsection{TEM Characterization of HgNPs}

Figure 3 demonstrates the TEM images along with a size distribution chart of the Ibu-HgNPs formed under optimized conditions on a carbon-coated copper grid.

The images show the formation of broadly distributed spherical HgNPs. The size distribution chart depicts the range of HgNPs from 1-8 nm with an average diameter of $3.5 \pm 1.2 \mathrm{~nm}$. The small sizes of these nanoparticles indicate that they can possess good catalytic properties. These results are in agreement with previous studies [21,22]. The following mechanism for the formation of Ibu-HgNPs in solution can be proposed (Figure 4). 

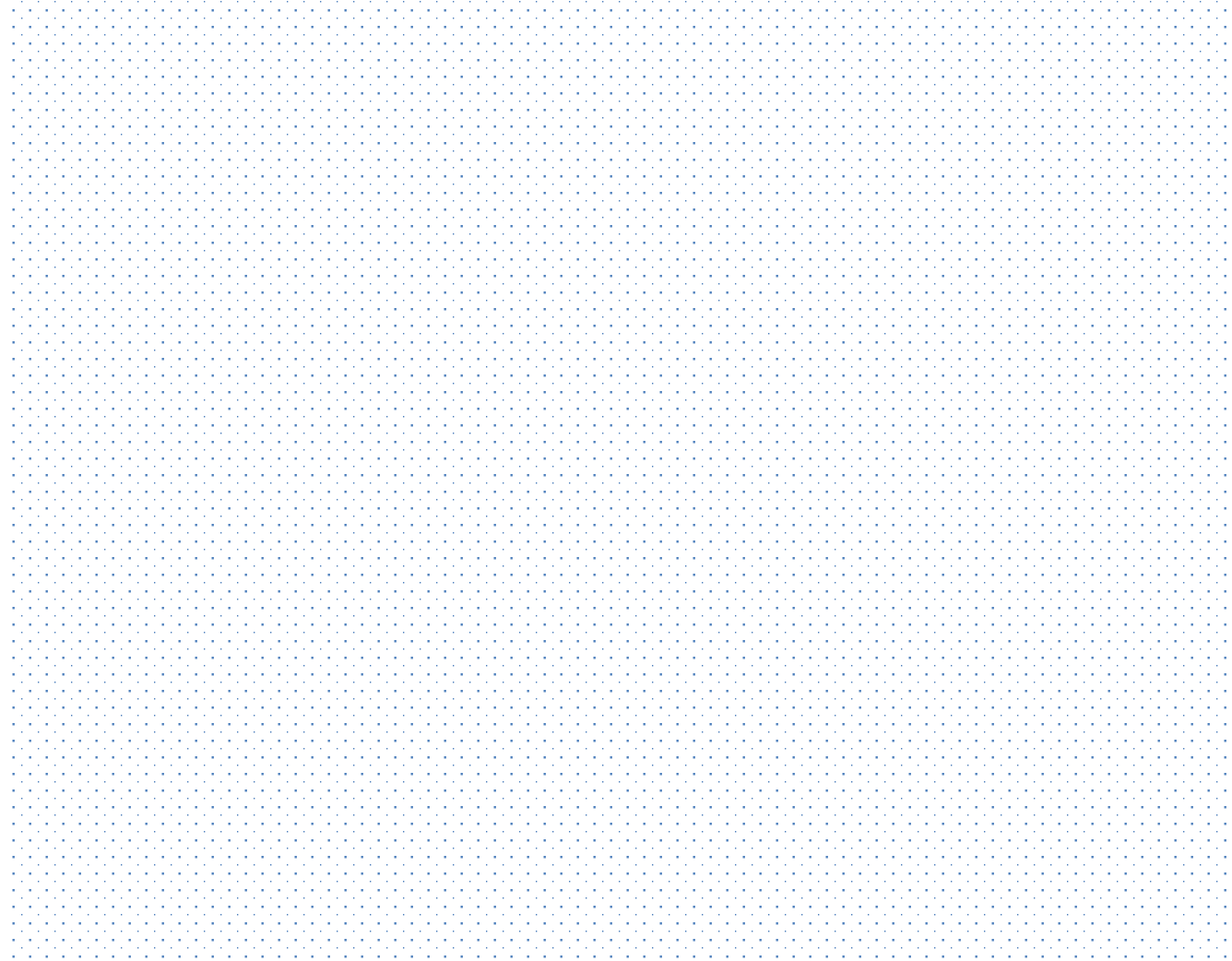

Figure 3. TEM images (a,b) and size distribution chart (c) of prepared IbuHgNPs.

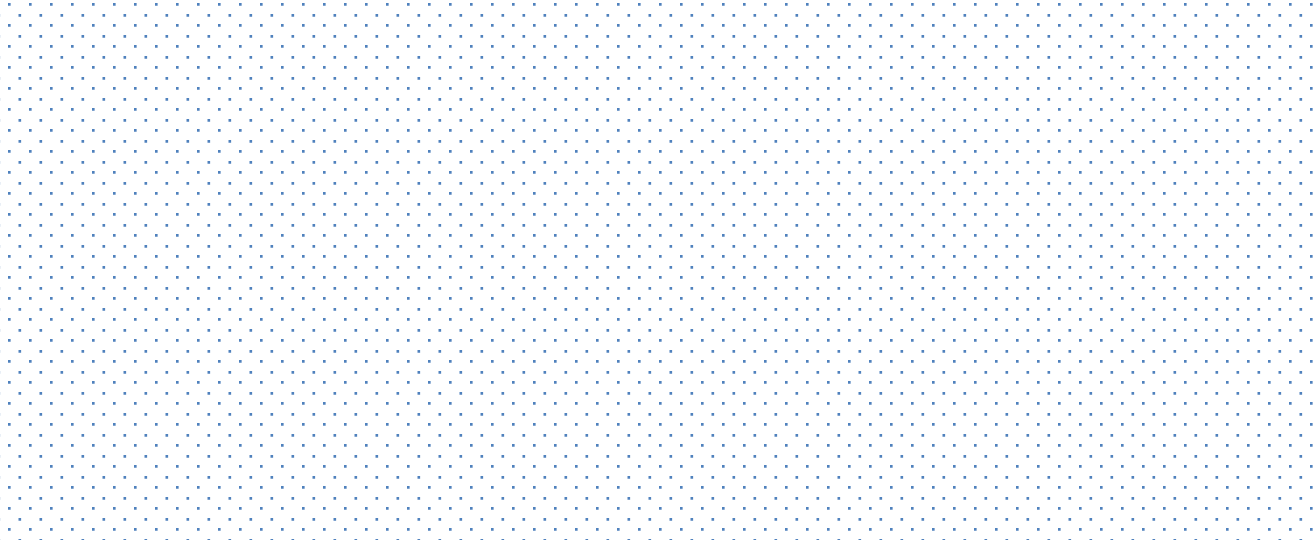

Figure 4. Proposed mechanism for the formation of Ibu-HgNPs in solution.

Here, $\otimes$ represents the $\mathrm{Hg}^{2+}$ ions in aqueous solution and I-COO-O or O-OOC-I show the interaction of ibuprofen with $\mathrm{HgNPs}$, resulting in their stabilization against agglomeration. Firstly, hydrazine $\left(\mathrm{N}_{2} \mathrm{H}_{2}\right)$ is converted into gaseous $\mathrm{N}_{2}$ and $\mathrm{H}_{2}$ where $\mathrm{N}_{2}$ plays the role of remover of oxygen from water, thus hindering oxygen attack on HgNPs and hence avoiding the formation of $\mathrm{HgO}$, while $\mathrm{H}_{2}$ works as a strong reducer for the conversion of $\mathrm{Hg}^{2+}$ ions into HgNPs. Ibuprofen (represented as I-COOH in Figure 4) is present at the used $\mathrm{pH}$ in dissociated-form $\mathrm{I}^{-\mathrm{COO}^{-}}$. As soon as the HgNPs are formed via reduction by hydrazine, the ibuprofen interacts with HgNPs to keep them small and stabilized against agglomeration. The TEM images in Figure 3 prove the presence of small and ibuprofen-stabilized HgNPs.

\subsection{Voltammetric Study}

At first, optimization of various parameters of the voltammetric determination of AA via Ibu-HgNPs-GCE in aqueous system was carried out. The following parameters were 
optimized using $1000 \mathrm{ppb}$ standard solution of AA, Ibu-HgNPs-GCE and $240 \mathrm{~s}$ bubbling with nitrogen to remove oxygen.

\subsubsection{Effect of Different Supporting Electrolytes}

Here, $0.05 \mathrm{~mol} \mathrm{~L}^{-1} \mathrm{LiCl}$, TMAB, TMAI and TBAI were tested to determine the AA using DPV at Ibu-HgNPs-GCE in the potential range of $-0.1 \mathrm{~V}$ to $-2.0 \mathrm{~V}$ in aqueous solution (see Figure 5a). Tested buffers are frequently used in our laboratory with satisfactory results and thus we did not feel it was necessary to test a large number of other available buffers. The highest and best developed peaks were obtained using TMAB and $\mathrm{LiCl}$. Therefore, we further tested various combinations of $\mathrm{LiCl}$ and $\mathrm{TMAB}$.
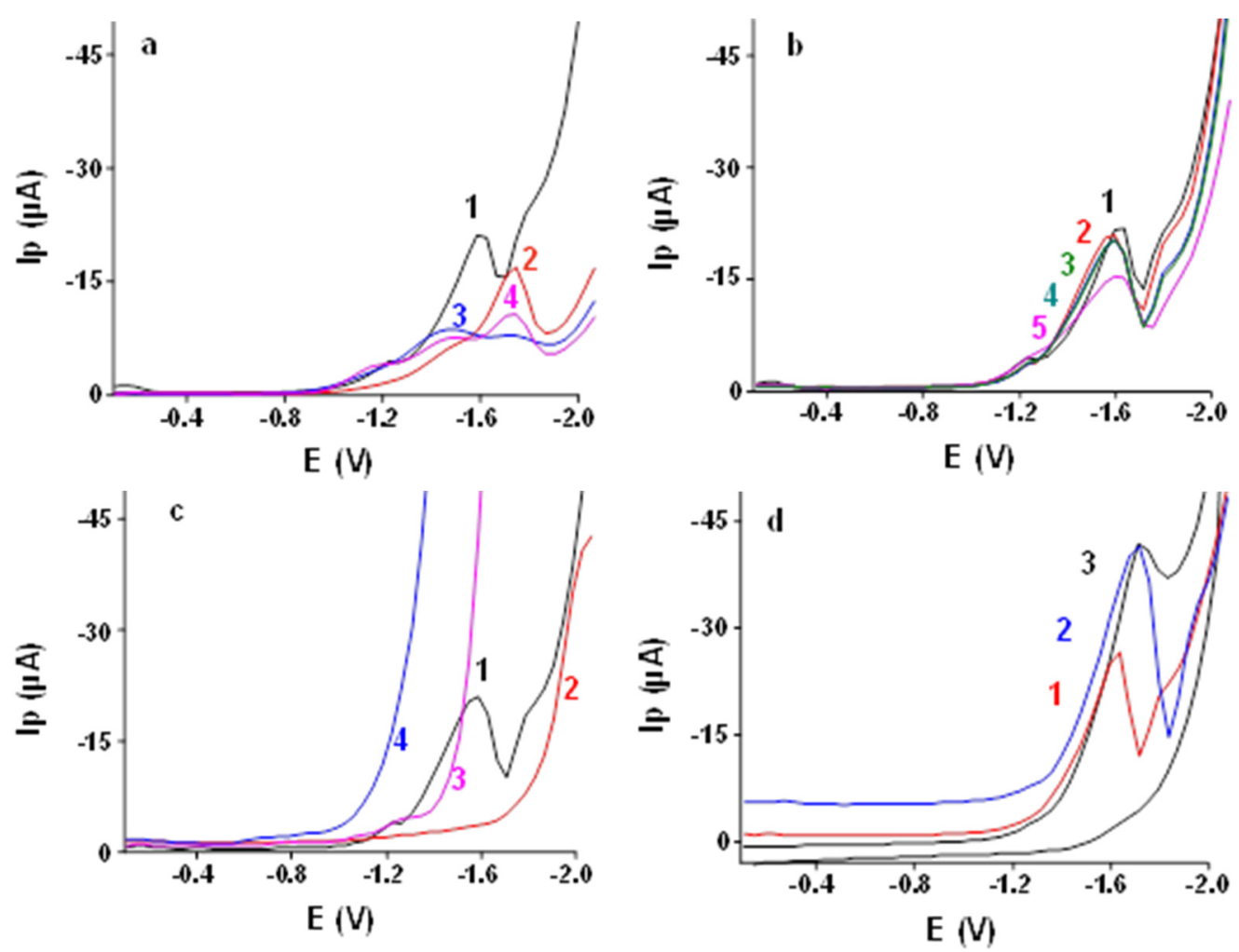

Figure 5. DP voltammograms of $1000 \mathrm{ppb}$ AA at Ibu-HgNPs-GCE, (a) Effect of different supporting electrolytes, (1) TMAB, (2) LiCl, (3) TMAI, (4) TBAI (each $0.05 \mathrm{~mol} \mathrm{~L}^{-1}$ ); (b) Effect of different ratios of LiCl:TMAB (each 0.05 mol L${ }^{-1}$ ), (1) 9:1, (2) 8:2, (3) 7:3, (4) 6:4, (5) 5:5 TBAI; (c) Effect of different working electrodes, (1) Ibu-HgNPs-GCE, (2) bare GCE, (3) bare AgE, (4) bare AuE; (d) Effect of different voltammetric techniques, (1) DPV, (2) SWV, (3) CV.

\subsubsection{Effect of Ratio of $\mathrm{LiCl}$ to $\mathrm{TMAB}$ in Supporting Electrolytes}

Different $v / v$ ratios of $0.05 \mathrm{~mol} \mathrm{~L}^{-1} \mathrm{LiCl}$ and TMAB $(9: 1,8: 2,7: 3,6: 4,5: 5)$ were tested using DPV at Ibu-HgNPs-GCE (Figure 5b). The best results were obtained with $0.05 \mathrm{~mol}$ $\mathrm{L}^{-1} \mathrm{LiCl}$ to $0.05 \mathrm{~mol} \mathrm{~L}^{-1} \mathrm{TMAB}$ at a $v / v$ ratio $8: 2$, which was used for further optimization.

\subsubsection{Comparison of Different Working Electrodes}

For the sake of comparison, various working electrodes (Ibu-HgNPs-GCE, bare GCE, bare silver electrode $(\mathrm{AgE})$ and bare gold electrode $(\mathrm{AuE})$ ) were used for determination of $1000 \mathrm{ppb}$ AA (Figure 5c) in $0.05 \mathrm{~mol} \mathrm{~L}^{-1} \mathrm{LiCl}$ and $0.05 \mathrm{~mol} \mathrm{~L}^{-1} \mathrm{TMAB}(v / v$ ratio 8:2). It was obvious that HgNPs-GCE was the best electrode for AA determination in comparison with other electrodes. Hence, Ibu-HgNPs-GCE was used for further studies. 


\subsubsection{Comparison of Different Voltammetric Techniques}

Various voltammetric techniques $(\mathrm{CV}, \mathrm{DPV}$, and $\mathrm{SWV})$ were tested for determination of $1000 \mathrm{ppb}$ AA on Ibu-HgNPs-GCE (see Figure 5d). CV revealed that the AA reduction on HgNPs-GCE was irreversible, which was in agreement with paper [17], which assumes irreversible reduction of AA to propionamide via two electrons' and two protons' transfer. However, our paper is focused on voltammetric determination of AA and thus the mechanism of its electrode reaction was not investigated in detail. Both the peak shape and height and background current were optimal in the case of SWV (in the case of DPV, the observed peak current of AA was somewhat lower). Therefore, SWV was used for further studies.

\subsubsection{Effect of SWV Frequency}

The influences of various SWV frequencies on the peak current of $1000 \mathrm{ppb}$ AA $(10,20$, 30, 40, 50, 60, 70, 80, 90 and $100 \mathrm{~Hz}$ ) at Ibu-HgNPs-GCE were tested (see Figure 6a). It can be seen that with increasing frequency, the SWV peak current of AA increases, with a slight shift of the peak potential towards more negative values. A frequency higher than $50 \mathrm{~Hz}$ generates distortion and a broadening effect with an additional shoulder peak. Therefore, the $50 \mathrm{~Hz}$ frequency was selected for further studies.

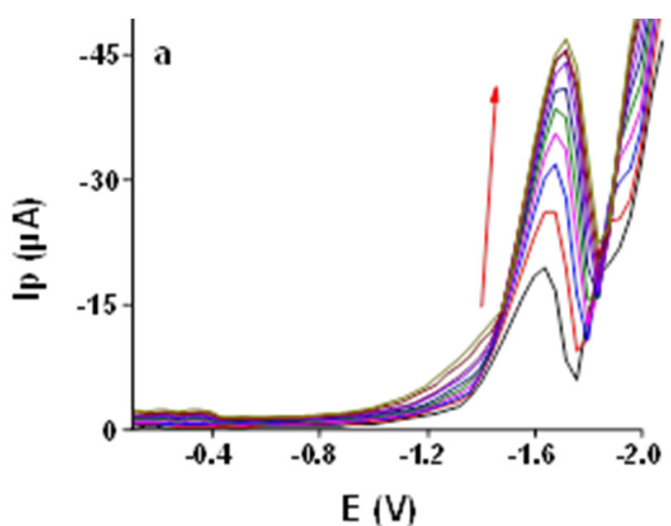

$\mathrm{E}(\mathrm{V})$

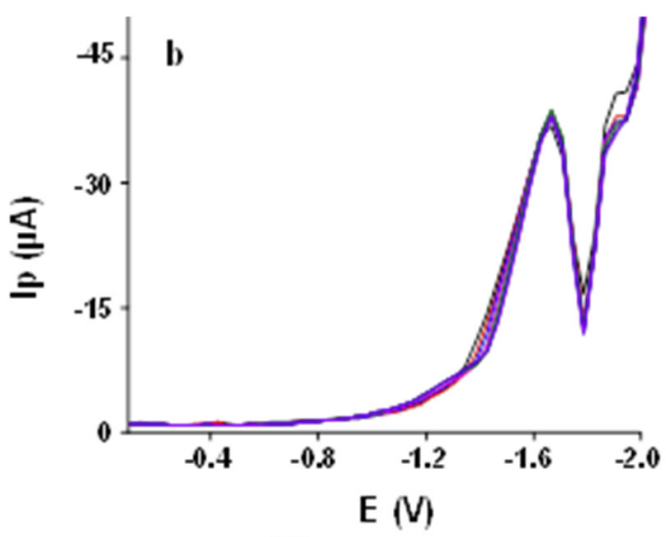

$\mathrm{E}(\mathrm{V})$

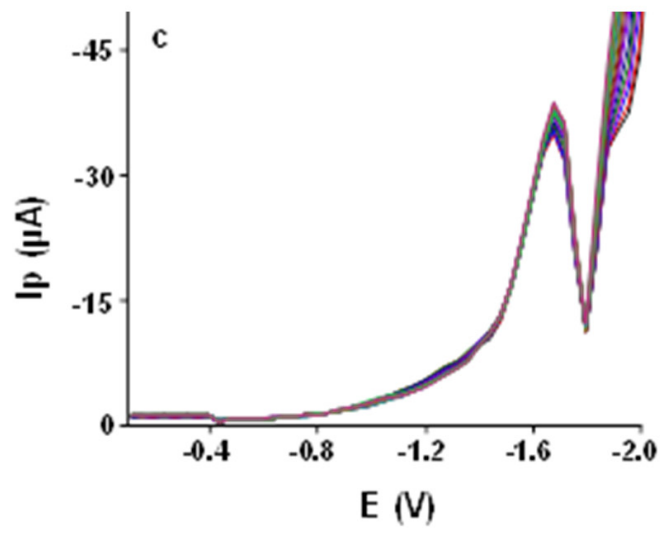

Figure 6. Effect of different parameters on SWV of $1000 \mathrm{ppb}$ AA at Ibu-HgNPs-GCE in $0.05 \mathrm{~mol} \mathrm{~L}^{-1}$ $\mathrm{LiCl}$ and $0.05 \mathrm{~mol} \mathrm{~L}^{-1} \mathrm{TMAB}(v / v$ ratio 8:2). (a) Various frequencies $(10,20,30,40,50,60,70,80,90$, $100 \mathrm{~Hz}$ ), accumulation time $0 \mathrm{~s}$, stirring rate $0 \mathrm{rpm}$. (b) Accumulation time from 0 to $360 \mathrm{~s}$, stirring rate $0 \mathrm{rpm}$, frequency $50 \mathrm{~Hz}$. (c) Stirring rate from 0 to $3000 \mathrm{rpm}$, frequency $50 \mathrm{~Hz}$, accumulation time $60 \mathrm{~s}$.

\subsubsection{Effect of Accumulation Time and Stirring Rate}

The effect of accumulation time from 0 to $360 \mathrm{~s}$ was studied using Ibu-HgNPs-GCE for $1000 \mathrm{ppb}$ of AA at the deposition potential of $-0.4 \mathrm{~V}$ (Figure $6 \mathrm{~b}$ ) and stirring rate of $1000 \mathrm{rpm}$. A negligible effect was observed on the peak current and the same held for the stirring rate during accumulation (Figure $6 \mathrm{c}$ ). Therefore, accumulation was not used in further studies. 


\subsubsection{Effect of Initial Potential}

Different initial potential values $(-0.1,-0.2,-0.4,-0.6,-0.8,-1.0,-1.1 \mathrm{~V})$ were applied to see their effect on the peak current of $1000 \mathrm{ppb}$ AA using SWV at Ibu-HgNPsGCE (see Figure 7a). The peak current decreased with decreasing initial potential. Hence, $-0.1 \mathrm{~V}$ initial potential was selected as optimum for further studies.
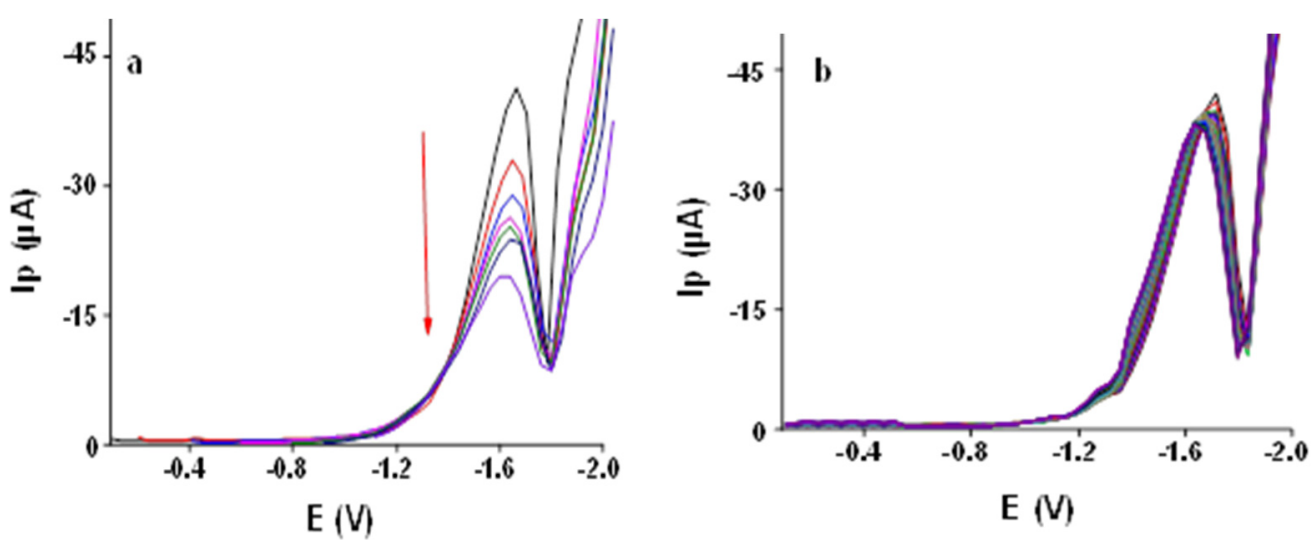

Figure 7. SW voltammograms $(50 \mathrm{~Hz})$ of $1000 \mathrm{ppb} \mathrm{AA}$ at Ibu-HgNPs-GCE in $0.05 \mathrm{~mol} \mathrm{~L}^{-1} \mathrm{LiCl}$ and $0.05 \mathrm{~mol} \mathrm{~L}^{-1} \mathrm{TMAB}(v / v$ ratio 8:2). (a) Effect of initial potential $(-0.1,-0.2,-0.4,-0.6,-0.8,-1.0$, $-1.1 \mathrm{~V})$. (b) Repeatability for 25 repeated voltammograms at optimum conditions given in 3.2.9.

\subsubsection{Repeatability Test}

Twenty-five repetitive SWV of $1000 \mathrm{ppb}$ AA at Ibu-HgNPs-GCE in $0.05 \mathrm{~mol} \mathrm{~L}^{-1}$ $\mathrm{LiCl}: \mathrm{TMAB}(8: 2 v / v$ ratio) are depicted in Figure $7 \mathrm{~b}$. The obtained relative standard deviation (RSD) of $1.4 \%$ proves the good performance and high stability of the newly developed sensor. This means that Ibu-HgNPs-GCE can be used for at least 25 consecutive measurements without appreciable decrease in response (negligible electrode passivation). Therefore, there is no need to renew the electrode surface after a few measurements. The electrode response is sufficiently stable for the whole day. If the performance of the electrode deteriorates for any reason, it can be renewed by repeating the procedure of its preparation. However, we could use the electrode for the whole day without any problem.

\subsubsection{Calibration Plot}

Calibration dependence was plotted in the broad concentration range of 100-1300 ppb AA using SWV at newly developed Ibu-HgNPs-GCE under the following optimized conditions, resulting from previous experiments (higher concentrations were not investigated because they are not realistically expected in drinking water): supporting electrolyte $0.05 \mathrm{~mol} \mathrm{~L}^{-1}, \mathrm{LiCl}-0.05 \mathrm{~mol} \mathrm{~L}^{-1}, \mathrm{TMAB} v / v$ ratio 8:2, Ibu-HgNPs-GCE, SWV in potential range from -0.1 to $-2.0 \mathrm{~V}$ with frequency of $50 \mathrm{~Hz}$. The corresponding plot (Figure $8 \mathrm{~b}$ ) shows excellent linearity $\left(R^{2}=0.9988\right.$ and LOD of $8.5 \mathrm{ppb}, 3 \mathrm{~s} / \mathrm{k}$, where $\mathrm{s}$ is the standard deviation of blank runs and $k$ is the slope of linear calibration plot [17]). 

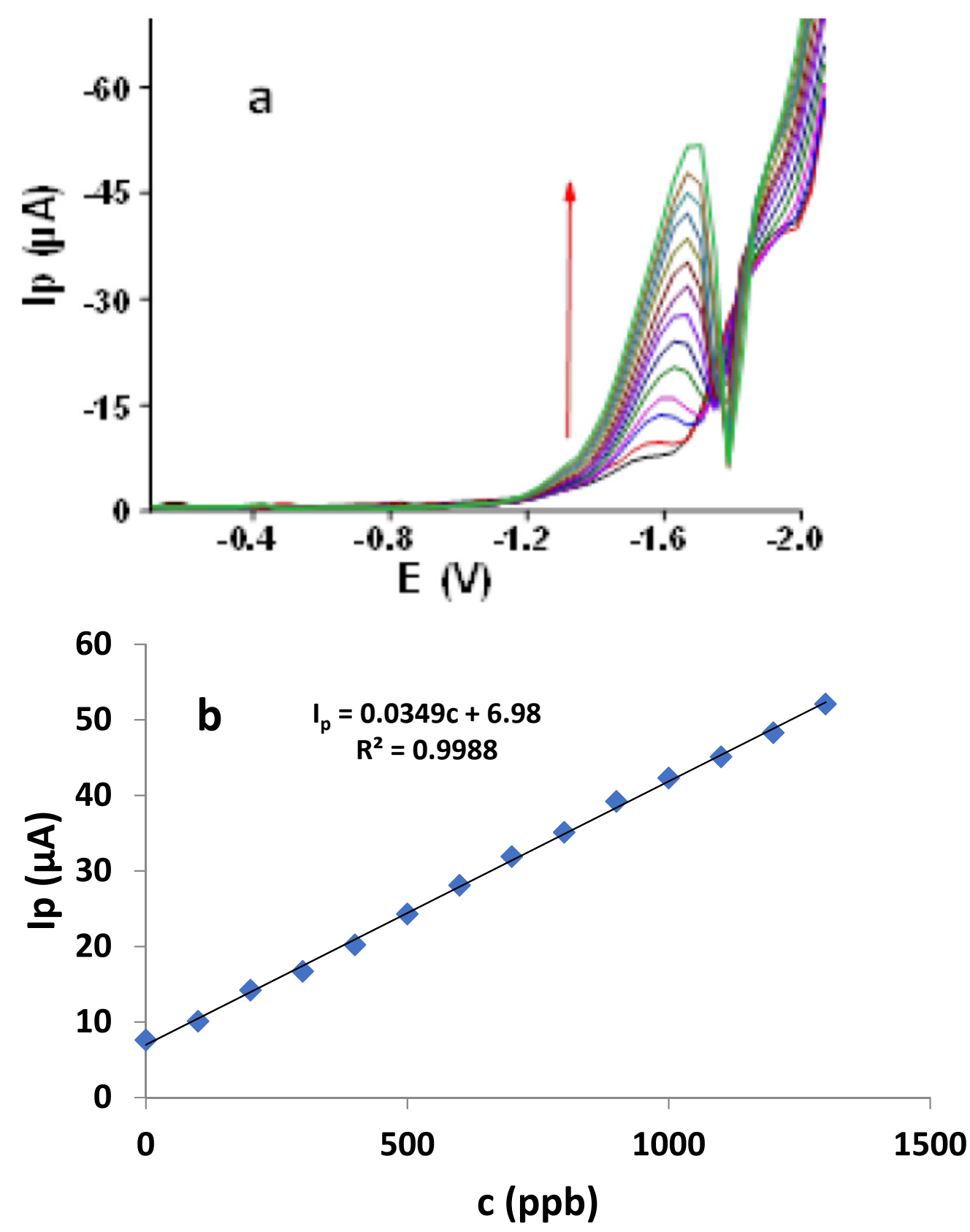

Figure 8. SWV $(50 \mathrm{~Hz})$ determination of $\mathrm{AA}$ at Ibu-HgNPs-GCE in $0.05 \mathrm{M} \mathrm{LiCl}$ and $0.05 \mathrm{M}$ TMAB $(v / v$ ratio 8:2). (a) Corresponding SW voltammograms (0 and 100-1300 ppb AA). (b) Corresponding linear calibration plot in the range of $0-1300 \mathrm{ppb}$ AA. Optimum conditions described in Section 3.2.9.

\subsubsection{Interferences}

The effect of interfering ions and compounds was studied to verify the selectivity of Ibu-HgNPs-GCE for 1000 ppb AA with a 10:1 ratio of interfering agent to AA, as shown in Table 1. It was evident that the effect of these individual interferents lay in the range of +0.5 to $-3.5 \%$, while the overall (combined) effect was equal to $-3.1 \%$. In other words, all these interferences were negligible within the acceptable range of $\pm 5.0 \%$. Therefore, our newly developed Ibu-HgNPs-GCE is highly selective for AA detection.

\subsubsection{Application of Ibu-HgNPs-GCE to Real Water Samples}

Ibu-HgNPs-GCE was applied for SWV determination of AA in real samples of local tap water with added concentrations of $200 \mathrm{ppb}, 500 \mathrm{ppb}$ and $700 \mathrm{ppb} \mathrm{AA}$ (with triplicate runs) (see Figure 9 and Table 2). The range of recovery of AA was between $99.8-100.2 \%$, with an 
average recovery of $99.6 \%$. The recovery value of AA in the mentioned samples confirms the applicability of the Ibu-HgNPs-GCE sensor for monitoring of AA in water samples.

Table 1. Influence of possible interferents (each with $10 \mathrm{ppm}$ concentration) on SWV determination of $1000 \mathrm{ppb}$ AA under optimum conditions described in Section 3.2.9. Interference in \% means the relative increase (+) or decrease (-) in SWV peak current of $1000 \mathrm{ppb}$ AA (taken as $100 \%$ ).

\begin{tabular}{cc}
\hline Interferent & Interference, \% \\
\hline $\mathrm{K}^{+}$ & +1.2 \\
$\mathrm{Na}^{+}$ & +1.5 \\
$\mathrm{Ca}^{2+}$ & +2 \\
$\mathrm{NH}_{4}{ }^{+}$ & +2.6 \\
Acetone & -1.1 \\
Formaldehyde & -1.5 \\
Acrolein & +0.7 \\
Acrylic acid & +0.5 \\
Maleic acid & -3.5 \\
Glucose & -2.1 \\
Citric acid & -3.4 \\
Starch & +0 \\
\hline
\end{tabular}
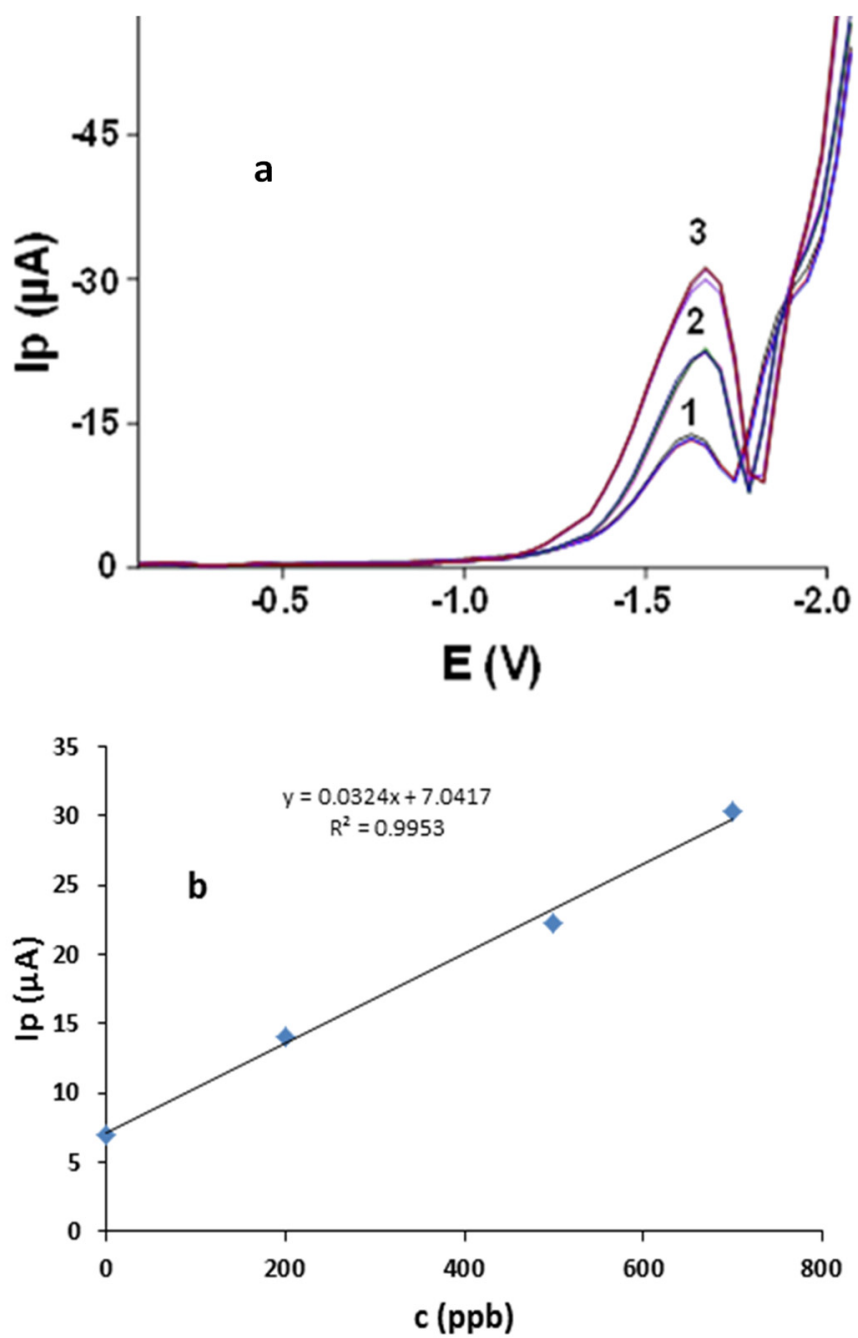

Figure 9. Three triple-performed SW voltammograms at Ibu-HgNPs-GCE of model local tap water sample with added 200, 500 and $700 \mathrm{ppb}$ of AA under optimized conditions described in Section 3.2.9 (a) and corresponding calibration dependence (b). 
Table 2. SWV determination of AA at Ibu-HgNPs-GCE in local tap water under optimized conditions described in Section 3.2.9. Average from three determinations.

\begin{tabular}{cccc}
\hline Local Water Sample & AA Added $(\mathbf{p p b})$ & AA Found \pm SD $(\mathbf{p p b}){ }^{*}$ & Recovery (\%) \\
\hline 1 & 0 & $-{ }^{\text {a }}$ & \\
2 & 200 & $198 \pm 0.6$ & 99 \\
3 & 500 & $501 \pm 0.4$ & 100.2 \\
4 & 700 & $699 \pm 1$ & 99.8 \\
& & & Mean 99.6 \\
\hline
\end{tabular}

a Below LOD of the proposed method; * calculated from three measurements.

The determination of AA was also performed in the Indus River water samples (again in triplicate) obtained from various sites in Hyderabad, Pakistan, with added concentrations of $200 \mathrm{ppb}, 500 \mathrm{ppb}$ and $700 \mathrm{ppb}$ AA (see Table 3). The recovery in this case was found to be from $98.3-101.0 \%$. RSD in Indus River water is, however, higher than in tap water due to a more complex matrix. Nevertheless, Ibu-HgNPs-GCE is also applicable to these types of complex environmental aqueous matrices.

Table 3. SWV determination of AA at Ibu-HgNPs-GCE in water of River Indus collected at three different sites with added 200, 500 and 700 ppb of AA. Optimized conditions described in Section 3.2.9. Average from three determinations.

\begin{tabular}{cccc}
\hline Indus River Water & AA Added $^{\mathbf{a}} \mathbf{( p p b )}$ & AA Found \pm SD (ppb) & Recovery (\%) \\
\hline Kotri site & 150 & $148 \pm 3.8$ & 98.7 \\
Al-Manzar site & 300 & $295 \pm 2.8$ & 98.3 \\
Jamshoro site & 500 & $505 \pm 4.1$ & 101 \\
\hline
\end{tabular}

${ }^{a}$ In unspiked samples, AA concentration was below LOD of the proposed method.

According to EPA, USA, the maximum contaminant level (MCL) in drinking water for a $10 \mathrm{~kg}$ child for one day of consumption is $1500 \mathrm{ppb}$, while for 10 days of consumption, it is $300 \mathrm{ppb}$. We worked on 300, 500 and $700 \mathrm{ppb}$ and our developed method was justified and practically applicable below or above an MCL of $300 \mathrm{ppb}$. For further detail, refer to the reference information at https://nepis.epa.gov /Exe/ZyPDF.cgi/600012B6.PDF?Dockey= 600012B6.PDF (accessed on 1 October 1995).

\section{Conclusions}

Mono-dispersed HgNPs were synthesized in an aqueous medium via hydrazineassisted reduction and an ibuprofen capping protocol at room temperature, and characterized via UV-Vis spectroscopy and TEM. UV-Vis spectroscopy revealed the existence of an absorption band of Ibu-HgNPs at around $320 \mathrm{~nm}$, while TEM analysis verified the existence of these Ibu-HgNPs in a solid form on the electrode surface with an average size of $3.5 \pm 1.2 \mathrm{~nm}$. Ibuprofen played a crucial role in the stabilization and size control of HgNPs. Nafion ${ }^{\mathrm{TM}}$ deposition provided the best adherence and stabilization of Ibu-HgNPs at the surface of GCE and thus contributed as the ideal material for Ibu-HgNPs' binding and long-term activity of modified GCE. Moreover, Nafion ${ }^{\mathrm{TM}}$, as a perfluorinated polymeric resin possessing cation exchange properties with enhanced mechanical resistance, can work as an active fence. Due to cation exchange properties, the exchange of $\mathrm{H}^{+}$ions on the polymer/electrode surface is increased, which gives rise to enhanced sensitivity in redox behavior. In addition, it also modifies the reproducibility and hence stability of the voltammetric responses. Due to such properties, Nafion is frequently used for modification of electrodes and thus we used it in this study as well [23].

Table 4 compares the results of AA determination using methods published so far $[17,21,22,24-26]$ with the current study. It is evident that most of the electrochemical sensors are less sensitive when compared to our newly developed sensor. The most sensitive sensor reported so far is that in paper [25]. However, due to the use of several serial modifications, it is not cost-effective or simple. 
Table 4. Comparison of published voltammetric methods for determination of acrylamide.

\begin{tabular}{ccccc}
\hline Technique & Electrode & Linear Range & LOD & Reference \\
\hline DP polarography & DME & $0.2-20 \mathrm{ppm}$ & $27 \mathrm{ppb}$ & {$[17]$} \\
\hline DPV & $\begin{array}{c}\text { AuNPs-MWCNTs- } \\
\text { CS-GCE }\end{array}$ & $0.05-5 \mathrm{ppm}$ & $28 \mathrm{ppb}$ & {$[21]$} \\
\hline SWV & DNA/HG/SPGE & $0.142-355.4 \mathrm{ppm}$ & $11.23 \mathrm{ppb}$ & {$[22]$} \\
\hline Polarography & DME & $100-5000 \mathrm{ppm}$ & $70 \mathrm{ppm}$ & {$[24]$} \\
\hline DPV & $\begin{array}{c}\text { SH-ssDNA-Au } \\
\text { electrode }\end{array}$ & $0.028-14216 \mathrm{ppm}$ & $0.58 \mathrm{ppb}$ & {$[25]$} \\
\hline Amperometry & $\begin{array}{c}\text { Co-phthalocyanine } \\
\text { modified SPE }\end{array}$ & $0.5-3500 \mathrm{ppm}$ & $355 \mathrm{ppb}$ & {$[26]$} \\
\hline SWV & HgNPs-GCE & $0.1-1.3 \mathrm{ppm}$ & $8.5 \mathrm{ppb}$ & This work \\
\hline
\end{tabular}

$\overline{\mathrm{LOD}}$, limit of detection; DPV, differential pulse voltammetry; SWV, square-wave voltammetry; DME, dropping mercury electrode; MWCNTs, multi walled carbon nanotubes; HG, hemoglobin; SPGE, screen printed gold electrode; SH-ssDNA, Thio group-single strand DNA.

Ibu-HgNPs deposited on GCE were used for the first time as highly sensitive and extremely selective modifiers for trace determination of AA in various water samples. The newly developed voltammetric AA sensor is simple and easy to construct, with a fast response, low cost and high stability, sensitivity and selectivity. Moreover, Ibu-HgNPs are more environmentally friendly than liquid mercury used in classical dropping mercury electrodes and/or hanging mercury electrodes, which are so far insurmountable working electrodes for the cathodic region. The portability of voltammetric equipment combined with this novel electrode and its application for on-site large-scale monitoring underlines the usefulness of this approach. Presumably, it can be used for highly selective and sensitive SWV determination of AA not only in environmental water samples but also in clinical, industrial, agricultural and other environmental samples. Further research is under way combining the newly introduced electrode with a preliminary separation and preconcentration from more complex samples.

Author Contributions: S.: Conceptualization, supervision, project administration and writingreview and editing. Z.A.T.: Investigation, formal analysis and writing-original draft. M.A.U.H.: Formal analysis, writing original draft and calculations. M.R.S.: Characterization, visualization, validation and software. M.-u.-R.: Investigation and writing-original draft. S.T.H.S.: Investigation, data curation and writing-original draft, review and editing. J.B.: conceptualization, supervision, project administration, writing — review and editing, funding acquisition and methodology. M.S.K.: Visualization, methodology, software and editing original draft. All authors have read and agreed to the published version of the manuscript.

Funding: J.B. thanks the Grant Agency of the Czech Republic (Project 20-01589S).

Institutional Review Board Statement: Not applicable.

Informed Consent Statement: Not applicable.

Data Availability Statement: Not applicable.

Acknowledgments: The authors are highly thankful to the Director of HEJ Research Institute of Chemistry, ICCBS, University of Karachi, for his leadership and support of this research. The authors also wish to thank Metrohm CZ (https:/ /www.metrohm.com/cs-cz/) (accessed on 1 October 2021) for providing material, technical and intellectual support.

Conflicts of Interest: The authors declare no conflict of interest. 


\section{References}

1. Friedman, M. Chemistry, biochemistry and safety of acrylamide: A Review. J. Agric. Food Chem. 2003, 51, 4504-4526. [CrossRef] [PubMed]

2. Alpmann, A.; Morlock, G. Rapid and sensitive determination of acrylamide in drinking water by planar chromatography and fluorescence detection after derivatization with dansulfinic acid. J. Sep. Sci. 2008, 31, 71-77. [CrossRef]

3. Kurenkov, V.F.; Hartan, H.-G.; Lobanov, F.I. Application of polyacrylamide flocculants for water treatment. Chem. Comput. Simul. Butl. Commun. 2002, 3, 31-40.

4. Dearfield, K.L.; Douglas, G.R.; Ehling, U.H.; Moore, M.M.; Sega, G.A.; Brusick, D.J. Acrylamide: A review of its genotoxicity and an assessment of heritable genetic risk. Mutat. Res. 1995, 330, 71-99. [CrossRef]

5. Casella, I.G.; Pierri, M.; Contursi, M. Determination of acrylamide and acrylic acid by isocratic liquid chromatography with pulsed electrochemical detection. J. Chromatogr. A. 2006, 1107, 198-203. [CrossRef] [PubMed]

6. Geng, Z.; Jiang, R.; Chen, M. Determination of acrylamide in starch-based foods by ion-exclusion liquid chromatography. J. Food Compos. Anal. 2008, 21, 178-182. [CrossRef]

7. Zhu, Y.; Li, G.; Duan, Y.; Chen, S.; Zhang, C.; Li, Y. Application of the standard addition method for the determination of acrylamide in heat-processed starchy foods by gas chromatography with electron capture detector. Food Chem. 2008, 109, 899-908. [CrossRef] [PubMed]

8. Bermudo, E.; Moyano, E.; Puignou, L.; Galceran, M.T. Determination of acrylamide in foodstuffs by liquid chromatography ion-trap tandem mass-spectrometry using an improved clean-up procedure. Anal. Chim. Acta 2006, 559, 207-214. [CrossRef]

9. Tarrke, E.; Rudberg, P.; Karlsen, P.; Eriksson, S.; Tornqvist, M. Analysis of acrylamide, a carcinogen formed in heated foodstuffs. J. Agric. Food Chem. 2002, 50, 4998-5006. [CrossRef] [PubMed]

10. Cavalli, S.; Polesello, S.; Saccani, G. Determination of acrylamide in drinking water by large-volume direct injection and ion-exclusion chromatography-mass spectrometry. J. Chromatogr. A 2004, 1039, 155-159. [CrossRef] [PubMed]

11. Barber, D.S.; Hunt, J.; Pachin, R.M.L.; Ehrich, M. Determination of acrylamide and glycidamide in rat plasma by reversed-phase high performance liquid chromatography. J. Chromatogr. B 2001, 758, 289-293. [CrossRef]

12. Singh, P.; Singh, P.; Raja, R.B. Determination of acrylamide concentration in processed food products using normal phase high performance liquid chromatography (HPLC). Afr. J. Biotechnol. 2010, 9, 8085-8091.

13. Karasek, L.; Wenzl, T.; Anklam, E. Determination of acryl amide in roasted chest nuts and chestnut-based foods by isotopes dilution HPLC-MS/MS. Food Chem. 2009, 114, 1555-1558. [CrossRef]

14. Hu, Q.; Fu, Y.; Xu, X.; Qiao, Z.; Wang, R.Y.; Zhang, Y. Li, A colorimetric detection of acrylamide in potato chips based on nucleophile-initiated thiol-ene Michael addition. Analyst 2016, 141, 1136-1143. [CrossRef]

15. Baharinikoo, L.; Chaichi, M.J.; Ganjali, M. Detecting the quantity of acrylamide in potato chips utilizing CdTe surface functionalized quantum dots with fluorescence spectroscopy. Int. J. Pept. Res. Therap. 2020, 26, 823-830. [CrossRef]

16. Zargar, B.; Sahraie, N.R.; Khoshnam, F. Catalytic square-wave voltammetric determination of acrylamide in Potato Chips. Anal. Lett. 2009, 42, 1407-1417. [CrossRef]

17. Niaz, A.; Sirajuddin; Shah, A.; Bhanger, M.I.; Saeed, M.; Jamali, M.K.; Arain, M.B. A new simple sensitive differential pulse polarographic method for the determination of acrylamide in aqueous solution. Talanta 2008, 74, 1608-1614. [CrossRef]

18. Krajewska, A.; Radecki, J.; Radecka, H.A. Voltammetric biosensor based on glassy carbon electrodes modified with single-walled carbon nanotubes/hemoglobin for detection of acrylamide in water extracts from potato crisps. Sensors 2008, 8, 5832-5844. [CrossRef]

19. Liu, X.; Mao, L.-G.; Wang, Y.-L.; Shi, X.-B.; Liu, Y.; Yang, Y.; He, Z. Electrochemical sensor based on imprinted sol-gel polymer on AuNPs-MWCNTs-CS modified electrode for the determination of acrylamide. Food Anal. Methods 2016, 9, 114-121. [CrossRef]

20. Asnaashari, M.; Kenari, R.E.; Farahmandfar, R.; Abnous, K.; Taghdis, S.M. An electrochemical biosensor based on hemoglobinoligonucleotides modified electrode for detection of acrylamide in potato fries. Food Chem. 2019, 271, 54-61. [CrossRef]

21. Tagar, Z.A.; Sirajuddin; Memon, N.; Kalhoro, M.S.; O’Brien, P.; Malik, M.I.; Abro, M.A.; Hassan, N.H.; Kalwar, S.S.; Junejo, Y. Highly sensitive, selective and stable multi-metal ions sensor based on ibuprofen capped mercury nanoparticles. Sens Actuators $B$ 2012, 173, 745-751. [CrossRef]

22. Harika, V.H.; Penki, T.R.; Loukya, B.; Samanta, A.; Xu, G.-L.; Sun, C.-J.; Grinberg, I.; Deepak, F.L.; Amine, K.; Aurbach, D.; et al. Sustainable existence of solid mercury $(\mathrm{Hg})$ nanoparticles at room temperature and their applications. Chem. Sci. 2021, 12, 3226-3238. [CrossRef]

23. Ugo, P.; Cavalieri, F.; Rudello, D.; Moreto, L.M. Nafion Coated Electrodes as Voltammetric Sensors for Iron Analysis in Sediments and Pore Waters: An Example from the Lagoon of Venice. Sensors 2001, 1, 102-113. [CrossRef]

24. Macwilliams, D.C.; Kaufman, D.C.; Waling, B.F. Polarographic and spectrophotometric determination of acrylamide in acrylamide polymers and copolymers. Anal. Chem. 1965, 37, 1546-1552. [CrossRef]

25. Huang, S.; Lu, S.; Huang, C.; Sheng, J.; Zhang, L.; Su, W.; Xiao, Q. An electrochemical biosensor based on single-stranded DNA modified gold electrode for acrylamide determination. Sens. Actuators B 2016, 224, 22-30. [CrossRef]

26. Bucur, M.P.; Bucur, B.; Radu, G.L. Simple, selective and fast detection of acrylamide based on glutathione S-transferase. RSC Adv. 2018, 8, 23931-23936. [CrossRef] 